\title{
Family approaches to treatment for obsessive compulsive disorder
}

\section{Abordagem familiar no tratamento do transtorno obsessivo-compulsivo}

\author{
Gail Steketee ${ }^{\mathrm{a}}$ and Barbara Van Noppen ${ }^{\mathrm{b}}$

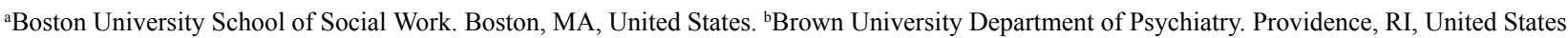

\begin{abstract}
This article reviews the family constellation of patients with obsessive compulsive disorder (OCD), the presence of OCD symptoms among family members, and familial aspects including parental attachment, expressed emotion (EE), and family accommodation. Some evidence supports a negative effect of hostility, emotional over-involvement, and criticism perceived by the patient on behavioral treatment outcome. However, actual criticism observed by the relative during an interview was associated with more benefit from therapy. Family accommodation predicted poorer family functioning and more severe OCD symptoms after behavioral treatment. A review of the limited treatment literature indicates no actual tests of the effects of psycho-educational and supportive treatments, although several reports suggest they are useful for families and patients. Including relatives in treatment has proved beneficial in some studies, especially with children, but not in others. Multiple family groups that focus on behavioral contracting for exposure and stopping rituals may be a promising intervention. Likewise, efforts to reduce family accommodation in the context of behavioral treatment have proved useful. Additional research on the content, process and effects of family interventions for OCD is much needed.
\end{abstract}

Keywords OCD. Expressed emotion. Behavior therapy. Family intervention. Exposure and response prevention.

Resumo Esse artigo revisa a constelação familiar dos pacientes com transtorno obsessivo-compulsivo (TOC), a presença de sintomas obsessivo-compulsivo entre os familiares e aspectos familiares como relacionamento parental, expressividade emocional e acomodação familiar. Algumas evidências sugerem que a hostilidade, o envolvimento emocional excessivo e criticismo observados pelo paciente têm um impacto negativo no seguimento do tratamento comportamental. No entanto, o criticismo, observado nos pais durante a entrevista, têm sido relacionado com melhor eficácia do tratamento comportamental. A acomodação dos familiares frente aos sintomas prediz um funcionamento familiar mais pobre, assim como maior gravidade do TOC depois do tratamento comportamental. Embora existam artigos sugerindo a utilidade de intervenções psico-educacionais e tratamentos de apoio, não existem trabalhos que tenham verificado a eficácia desses procedimentos. Incluir os familiares no programa de tratamento tem sido benéfico segundo alguns trabalhos, embora não confirmado em outros.Os grupos com várias famílias, dirigidos à programação da intervenção comportamental, podem ser uma intervenção promissora. Buscar a diminuição da acomodação familiar frente aos sintomas, dentro de um contexto de intervenção comportamental, têm também se mostrado útil. Pesquisas adicionais dirigidas às intervenções familiares no TOC são necessárias.

Descritores TOC. Emoções manifestas. Behavior therapy. Intervenção familiar. Exposição e resposta à prevenção.

\section{Introduction}

This paper will focus on family aspects that pertain to behavioral treatments for adults with obsessive compulsive disorder (OCD). Although family is particularly important for children and adolescents with this disorder, the issues are somewhat different than for adults and will not be addressed here. In this paper we will review findings from the research literature regarding genetic and familial relationships in the 
family of origin and how OCD affects families. In addition, several studies investigate family predictors of treatment outcome, especially family members' expression of emotion, and the effects of including family members in treatment. We will discuss the implications of these research findings for clinical intervention.

First, it is important to establish the family constellation typical for those with OCD. A large proportion of OCD sufferers are single, and this is especially evident among men, only $35 \%$ of whom have ever married compared to 60 to $75 \%$ of women. ${ }^{1}$ This difference may in part be due to the earlier onset of OCD in males. Although OCD in women typically begins in their early 20 s, for males, onset commonly occurs in middle adolescence, and can have profound developmental effects that disrupt education, socialization, sexual experience, and employment. The implication of these findings are that fewer than half of OCD treatment-seekers would benefit from marital interventions and approximately $25 \%$ of OCD adult patients will still be living with their parents. Nonetheless, many live with or maintain daily contact with parents or other family members. For treatment purposes, it may be important to remember that one-quarter of parents will have an OCD diagnosis and a somewhat higher percentage (30-40\%) will have subclinical obsessive symptoms and/ or obsessive personality traits. These symptoms and traits may lead to parents inadvertently reinforcing the child's OCD problems. Thus, family treatments must be directed at various types of family constellations and presume that some relatives may sympathize with and even encourage OCD behaviors.

Several studies address the quality of family relationships. Clinical experience and demographic data from several studies suggests a relatively low divorce rate (3-5\%) for married OCD patients. ${ }^{2}$ Studies of marriages suggest that 32 to $50 \%$ exhibit distressed relationships, but that scores on most measures fall in the normative range for the population. ${ }^{3,4}$ According to Riggs, Hiss and Foa, ${ }^{5}$ marital distress was not associated with severity of OCD symptoms or negative mood, but more maritally distressed patients engaged in more avoidance. With regard to family functioning, 50\% of OCD clinic patients scored in unhealthy range on one or more aspects, including affective responsiveness, roles, family problem solving, and/or behavior control. However, communication in families with an OCD member was not worse than in normative families. ${ }^{6}$ Even when greater family dysfunction is found, the causal directionality is unclear: Does OCD worsen family functioning or does poor family functioning exacerbate OCD symptoms or is the relationship transactional?

\section{OCD symptoms among family members}

Studies of transmission of OCD within families indicate only a modest tendency for OCD to occur among biological family members. The number of probands with OCD who have immediate family members with this disorder or a syndromal variant is approximately 20 to $25 \%$ of cases. ${ }^{7-10}$ Other types of mood and anxiety disorders occur at high rates among family members of patients with OCD. ${ }^{2,11,12}$ From a clinical standpoint, these findings mean that most adults who present for treatment will have grown up living with parents who themselves have some form of anxiety or depression. However, the limited information available indicates that relatives' depression and anxiety symptoms are not significantly related to patients' OCD symptoms or depression. ${ }^{13}$ As noted above, some patients with OCD will have grown up in households where parents also had this disorder. However, when OCD does occur in parents and their children, the symptom patterns are often different. ${ }^{10}$ For example, parents who have fears of harming and checking rituals may have children with washing rituals. This finding argues against observational learning as a major mode of transmission of OCD symptoms, though it is still possible that some general attitudes are learned in this way, such as excessive avoidance of danger or perfectionistic tendencies. Much remains to be learned about the relationship of these personality patterns and beliefs to OCD symptoms, although some studies have reported that the parents of those with OCD frequently exhibit such traits. ${ }^{14,15}$

\section{Parental bonding}

To study attachment to parents, Chambless, Gillis, Steketee, and Tran ${ }^{16}$ asked 52 adult OCD and 35 patients with panic and agoraphobia and their mothers and fathers to complete the Parental Bonding Instrument (PBI) which measures care and overprotection. Not surprisingly, clients rated parents more negatively than parents rated themselves, especially for maternal overprotection and paternal care. Parents were most likely to describe their parenting as having been optimal ( $46 \%$ mothers, $42 \%$ fathers), whereas clients most often reported affectionless control to have been most typical (41.2\% of mothers and $42.5 \%$ of fathers). Clients had a more global view of parental behavior in that they rated mothers and fathers similarly on care, whereas correlations between mothers' and fathers' ratings approached zero. Parents and their adult anxious children appear to have different views on past parental behavior. These clients' global view of their parents' styles (both were rated similarly) suggests that the clients' ratings may have more to do with their perceptions than with their parents' behavior. Although patient ratings of their parents were not related to mood or other pathology, poor social adjustment correlated with low parental care and more overprotection.

Modest relationships were found for anxious cluster personality traits and parental upbringing. More avoidant and dependent traits were found in clients who reported lower maternal care, whereas more dependent and passive-aggressive traits were found in those reporting higher maternal overprotectiveness. Ratings of fathers' bonding were not related to anxious personality traits. Overall, these findings suggest that poor parental bonding constitutes a general risk factor for psychopathology, rather than anxiety or OCD in particular. The finding that relationships were more apparent for maternal (especially care) rather than paternal variables is not surprising in a country where mothers are overwhelmingly likely to be the primary caretakers. Over-controlling parents 
may undermine the confidence of some offspring so that they become dependent, whereas others develop indirect ways to resist control. Our findings are in keeping with Bowlby's ${ }^{17}$ idea that, without a safe base in the bond with the parent, children become fearful of exploration and have difficulty developing appropriate independence.

\section{Effects of OCD on families}

It is hardly surprising that relatives find it stressful to live with a family member who has OCD. Cooper ${ }^{18}$ surveyed 225 family members of adults with OCD and reported that $75 \%$ experienced disruption in their lives because of the OCD, including loss of personal relationships, loss of leisure time, and financial problems. Several researchers have commented on the often extensive family involvement in patients' OCD symptoms. ${ }^{6,19}$ Approximately $75 \%$ of OCD relatives participated at least minimally in rituals or avoidance or modified their behavior to accommodate patients' symptoms. ${ }^{20-22}$ Accommodation include providing reassurance $(>30 \%)$, active participation in rituals and/or avoidance at patient's request (33-60\%), taking over patient duties ( $>33 \%)$, and modifying family activities and routines $(>35 \%)$. These efforts were usually intended to reduce patient distress and time spent on rituals. Not surprisingly, greater family participation was significantly related to distress in family members, ${ }^{13,20}$ as well as more rejecting attitudes. ${ }^{21}$ Interestingly, approximately $40 \%$ of family members felt responsible for their relative's OCD according to Calvocoressi and colleagues. Greater accommodation was also related to more family dysfunction, family stress, and rejecting attitudes toward the patient, suggesting that family interventions may be needed to address these difficulties. The limited research on treating family involvement in symptoms is reviewed below.

Studying children and adolescents and their parents, Hibbs et $\mathrm{al}^{23}$ concluded that family members of patients with OCD show high levels of expressed emotion (EE), defined as criticism, hostility and/or emotional over-involvement. Eightytwo percent of OCD families were rated as high on EE compared to families of a non-psychiatric control group in which $41 \%$ were rated high EE. The children from high EE families also showed more physiological reactivity than those from low EE families. ${ }^{24}$

\section{Familial predictors of outcome/relapse for OCD}

Although several predictors of immediate and long-term outcome of OCD symptoms have been examined, few studies have yielded consistent findings. ${ }^{25}$ Only a handful have examined family factors (marital satisfaction, family communication) as potential predictors of outcome, in contrast to the extensive literature on this topic in schizophrenia, mainly on expressed emotion (see below). Studies of family functioning in children with OCD indicate that one or both parents are often rated high on expressed emotion (EE), and EE levels have been associated with parental psychopathology. ${ }^{23,26}$ Leonard et $\mathrm{al}^{26}$ observed that parental lifetime psychiatric diagnosis predicted follow-up outcome, as did the number of parents with high EE, taken together with severity of OCD symptoms after medication. Unfortunately, these findings do not allow conclusions about family factors as predictors of outcome for behaviorally treated individuals, since few received this intervention.

Studies of behaviorally treated adults with OCD have yielded conflicting findings regarding family variables as predictors of outcome. Several researchers have proposed that family support is necessary for clients to benefit from behavioral therapy, ${ }^{27,28}$ but this is contradicted by other studies. In several studies, OCD patients from distressed marriages did not fare worse than those from non-distressed marriages. ${ }^{3,5,29}$ In fact, marital satisfaction improved after treatment regardless of pretreatment satisfaction, especially with regard to patient's demands and dependency on spouses. ${ }^{5,30}$ Thus exposure and response prevention treatment appears to be good for marriages.

\section{Expressed emotion}

Among the family variables examined as predictors of outcome in other mental disorders, expressed emotion (EE) appears to be the most studied construct. Numerous studies have indicated that EE (assessed mainly via a combination of criticism and emotional over-involvement) has been a consistent predictor of relapse for schizophrenia and depression, with findings replicated in many countries. ${ }^{31}$ Do EE and related constructs predict outcome for OCD? Steketee ${ }^{4}$ examined self and family-reported familial interactions in relation to outcomes 9 months after therapy. Pretreatment poor social and familial functioning, and patient-rated negative household interactions (anger, criticism, relatives' beliefs that the OCD patient was malingering) predicted fewer gains at follow-up. Conversely, positive feelings in the household predicted more improvement. These negative interaction variables resemble those coded for expressed emotion (EE) in other patient populations.

Emmelkamp, Kloek \& Blaauw ${ }^{32}$ included expressed emotion in their model of relapse in OCD. They hypothesized that relapse is likely when patients lack coping skills and social support or when they experience high EE in the face of stressors after treatment. They suggested that problems will be further compounded if relatives view OCD symptoms as a disease over which individuals have little control. This model has some overlap with a diathesis/stress model proposed for schizophrenics in which patient vulnerability to internal and environmental cues provoke symptoms which upset family members. These family members respond adaptively by engaging in problem solving with the patient or maladaptively by becoming over-involved or frustrated, angry, and rejecting. Maladaptive reactions provoke more stress in the patient, leading to more symptoms and eventual relapse. In a partial test of their relapse model for OCD, Emmelkamp et $\mathrm{al}^{32}$ found that the combination of EE ratings, avoidant coping style, and life events/daily hassles significantly predicted relapse $(\mathrm{r}=.44)$. Social support did not, consistent with previous findings by Steketee. ${ }^{4}$ High EE ratings at follow-up were evident in 3 of 4 clear relapses but in 
neither of the two partial relapses. The authors' recommended involving spouses or family members in treatment that emphasized empathic listening skills and communications training.

Chambless \& Steketee ${ }^{29}$ examined EE variables as predictors of behavioral treatment outcome in a mixed sample of 60 OCD patients and 41 agoraphobics with moderate to severe symptoms. Eleven patients refused to participate in this study because relatives refused or the patient was unwilling to include them. Patients received 22 sessions of exposure therapy with no family involvement in treatment except a brief assessment and education about the planned therapy. EE consisted of five variables (criticism, emotional over-involvement, hostility, warmth and positive remarks) coded by trained raters from the Camberwell Family Interview with relatives. Interestingly, the number of critical comments by family members ranged widely but the overall mean number was rather high compared to other patient samples; few relatives displayed hostility. Most criticisms focused on the patient's chronic sick role (lack of motivation, problematic personal habits, burden to the relative) and on their anxiety symptoms. Overall outcomes from the behavioral treatment were quite good, with substantial reductions in target symptoms after treatment and at 1-year follow-up.

Emotional over-involvement was associated with more dropout, as was hostility: those with hostile relatives were six times more likely to drop out. Hostility also predicted poor outcome after treatment. The patient's perception of more criticism was a significant predictor of poor outcome at posttest, and findings at follow-up were in the same direction but not significant. Interestingly, critical comments by relatives tended to predict better outcome, a finding also reported by Peter and $\mathrm{Hand}^{33}$ for panic patients. At follow-up, none of the EE variables predicted outcome, mainly because most patients who were affected by these problems before and after treatment were no longer included in the follow-up sample because they had dropped out or already failed to benefit.

These findings from research studies investigating family variables in relation to outcome for OCD are generally supportive of the need to take family interaction into consideration in planning treatment. With regard to expressed emotion, relative's criticism (made during a semi-structured interview when the patient is not present) does not appear to be problematic, so long as it is not hostile. In fact, criticism of OCD behaviors may serve as a motivator for patients to obtain therapy and to work on their problem during exposure treatment. Hostile criticism, however, is a serious problem and appears to make it difficult for patients to continue in treatment and to benefit from it. It is also clear from our findings that patient's perceptions that their relatives are critical of them interferes with benefits from treatment. Perceived criticism has been linked to the relative's report of criticism and with a lack of relative's positive comments, suggesting that patients are at least partly correct in their perceptions. However, perceived criticism is also correlated with negative personality traits in the patient, indicating that some aspects of this perception may simply reflect the patient's own negative attitudes and that these also interfere with benefits from therapy. More research is needed to clarify how perceived criticism works and whether it requires change in the patient or in the relative. For example, it is possible that problemsolving skills training for both patients and relatives will prove useful in resolving some of the OCD symptoms. Steketee, Van Noppen, Lam and Shapiro ${ }^{34}$ have suggested assessment and intervention strategies for reducing criticism, over-involvement and hostility during behavioral treatment.

Excessive accommodation on the part of relatives has also proved problematic. In a small sample of 17 OCD patients, Amir et $\mathrm{al}^{13}$ reported that greater family accommodation and modification of routine correlated with more severe OCD symptoms after treatment. One possible reason is that overinvolvement and accommodation decrease patients' sense of self-efficacy. More research is needed to determine whether emotional over-involvement is closely linked to relatives' excessive accommodation to patients' wishes with regard to OCD symptoms. So far, the link between these constructs has not been examined and since both appear to cause problems for the family as a whole, understanding them better will be important in determining how to intervene.

\section{Family treatment interventions}

Several researchers have noted advantages for support group involvement of both patients and family members. Marks, Hodgson, and Rachman ${ }^{35}$ employed an open-ended monthly group for family members and patients who had completed initial individual behavioral treatment for OCD. Family members discussed the impact of OCD symptoms on the family and plans for coping strategies and patients rehearsed behavioral exercises in the group. Recently, several reports have outlined psycho-educational foci for time-limited family support groups, including sessions on diagnosis, assessment, theories of OCD, behavioral treatment including exposure and stopping rituals, medications and prevention of relapse. ${ }^{11,18,36}$ Psycho-educational group goals included improving self-esteem, sharing feelings and experiences, accepting patients' realistic limitations, and learning strategies for coping with OCD symptoms. The use of co-leaders to respond adequately to the emotional needs of group members was encouraged. These reports noted high participant satisfaction with psychoeducational groups, but provided no outcome data.

As with other anxiety disorders, most quantitative family research in OCD has focused on the effect of including family members in behavioral treatment. Case studies showed advantages to parental involvement in treatment for children and young adults. ${ }^{37-39} \mathrm{In}$ a controlled study with a small sample, Emmelkamp and DeLange ${ }^{40}$ compared the outcome of Dutch clients treated behaviorally with or without the spouse as cotherapist. Unfortunately, the content of psycho-educational interventions aimed at reducing conflict or enhancing communication was not described. Patients treated with spouse assistance improved more at posttest, but not at follow-up. In a second larger study of 50 subjects, spouse assistance made 
no difference in outcome either after treatment or at followup, although improvement in marital satisfaction was reported. ${ }^{3}$ It is noteworthy that in these studies, spouses were not specifically trained in communication with the patient regarding their symptoms. However, in a later report, Emmelkamp and colleagues encouraged the inclusion of partners and emphasized empathic communication as an important factor in outcome. ${ }^{32}$

Emmelkamp et al's negative findings in a Dutch sample are contradicted by Mehta's ${ }^{41}$ study of family involvement in treatment in India. Involving family members in exposure and response prevention treatment for 30 patients in India led to significantly greater gains in OCD symptoms, moodstate, and social and occupational functioning compared with unassisted treatment at posttest and at follow-up. Mehta's sample included an equal number of spouses and parents. Non-anxious, firm family members were more successful in providing support and supervision than anxious and inconsistent ones, and especially those who engaged in argument and ridicule. This treatment was longer and more intense (24 sessions in 12 weeks) than Emmelkamp and colleagues' 8 sessions in 5 weeks. Hafner ${ }^{42}$ suggested that spouse-aided therapy for OCD may first require the overcoming of high levels of family hostility (akin to high expressed emotion) and proposed that Mehta's study may have employed a less confrontational family role. The discrepant findings could also reflect cultural differences in the in the style of family interaction, especially if Indian families were lower on EE as findings from other studies suggest. ${ }^{43}$

Two studies have focused on reducing family accommodation to OCD symptoms. Thornicroft, Colson and Marks ${ }^{44}$ reported an uncontrolled effort to reduce relative's involvement in OCD symptoms. Their inpatient treatment program in Great Britain emphasized self-treatment and teaching relatives to assist in the therapy program. Behavior therapy included exposure and response-prevention plus strategies for self-control and social skills training. The family component focused on reducing relatives' involvement in rituals by training them to monitor patient behavior and encourage self-exposure in a noncritical manner. Relatives practiced under the therapist's supervision on the ward. Findings indicated decreases in OCD symptoms of about $45 \%$ at discharge $(\mathrm{N}=45)$ and $60 \%$ at a 6 month follow-up ( $\mathrm{N}=22)$, with concomitant improvement in functioning ranging from $33 \%$ (work) to $48 \%$ (home) at follow-up. These findings indicated good success for this severe inpatient population who scored in the extreme range on disability from OCD symptoms.

A more recent trial by Grunes, Neziroglu and $\mathrm{McKay}^{45}$ examined the benefits of a relative's participation in an 8-week psycho-educational group designed to help reduce accommodation to OCD symptoms. Twenty-eight patients who received individual treatment via exposure and response prevention were randomly assigned to have their relative participate in the family group or not. Patients whose family member was involved in the group had greater reduction in OCD symptoms (Yale-Brown Obsessive Compulsive Scale [YBOCS] reduced from 27.0 to 18.4 ) and in depressed mood compared to those whose relatives did not participate (YBOCS reduced from 24.1 to 21.3). Gains were maintained at a 1-month follow-up and are all the more impressive because this group of patients was generally treatment refractory as evident from the minimal benefit in the family-untreated sample. Also, family accommodation, as well as depression and anxiety, was reduced in the relatives who participated in the educational group. Which aspect of change in relatives' behavior played a role in improved outcome in the patients is an important question for future research.

We completed an uncontrolled study of the effects of 10 to 12 weeks of multifamily behavioral treatment ${ }^{46}$ for 19 OCD adults and their family members. Family members and patients together received education about $\mathrm{OCD}$ and exposure treatment and were taught family contracting for behavior change, along with direct exposure during family group sessions. Six monthly follow-up sessions helped families review progress and identify additional needs. YBOCS scores reduced significantly at posttest from means of 23 to 17 and gains were maintained at follow-up, with additional benefits evident in family functioning. Poorer family functioning on roles and communication predicted worse outcome on OCD symptoms. These findings argue for the need for further study of this cost-effective multifamily method that has also proved very useful for treatment of patients with chronic mental illness. ${ }^{45}$ In particular, the long-term benefits of this method appear quite promising.

Reports of family intervention with childhood OCD are quite promising. Piacentini et $\mathrm{a}^{47}$ provided data on the use of psycho-education, disengagement from the child's OCD symptoms, and interventions for conflict and family disruption. Nearly $80 \%$ of 42 patients responded well (much improved) to this protocol, although not all received all of the family components. Recently, Waters, Barrett and $\mathrm{March}^{48}$ provided pilot data on the efficacy of a 14-week cognitive behavioral family treatment for 7 children with OCD. Treatment included components on education, parental participation in childhood relaxation training, reduction of accommodation, parental anxiety management, family support of ERP and problem solving skills training. This treatment package led to considerable benefits for 6 of the 7 children at posttest (child version of the YBOCS [CY-BOCS] reduced from a mean of 22.1 to 9.0) and for all at 3-month follow-up (average CY-BOCS was 6.9), although one child relapsed partially. Family accommodation also improved substantially.

The above studies are not yet so definitive that they clearly establish whether relatives' involvement in behavioral treatment of OCD significantly enhances outcome. However, findings appear promising. Fine-grained analyses have not yet indicated what traits characterize patients and family members who respond to these methods. Findings from the extensive literature on family characteristics of schizophrenics that have predicted outcome and family treatment for this disorder offer some direction for research on OCD in this regard.

Research on chronic mental illness suggests that group treat- 
ment and multifamily group interventions appear to have distinct advantages of efficiency and cost effectiveness over other formats for delivery of behavioral treatment. ${ }^{46}$ They may facilitate stress reduction and problem solving skills via ventilation and modeling within the group context. In view of the often extensive involvement of family members in OCD rituals and avoidance and the apparent predictive capacity of family variables in several studies of OCD, it is reasonable to hypothesize that treatments that include family members will be beneficial for many OCD patients and families. Further, the cost effectiveness of family group interventions and their potential value for enhancing coping (relapse prevention) skills acquired from observation of others argue for the need to evaluate outcomes from behavioral group treatment for OCD. Of interest in evaluating the outcome of such treatments is the determination of the processes by which these methods have their effect. The literature on outcome prediction indicates that fruitful avenues are likely to include assessment of expressed emotion, perceived criticism, and perceived family functioning.

An indirect study of family-related interventions is found in Hiss, Foa and Kozak's ${ }^{49}$ test of relapse prevention treatment appended to exposure and response prevention compared to a placebo intervention called associative therapy. The relapse prevention included a session with a significant other in which maladaptive interpersonal problems such as anger and criticism and unrealistic expectations by relatives were addressed, along with other components designed to reduce stress-related exacerbation of symptoms. Relapse prevention led to fewer relapses in OCD symptoms and to less depression and anxiety compared to placebo, but whether the intervention with relatives contributed to this is unknown.

\section{Conclusion}

\section{Summary and treatment recommendations}

Overall, what is needed is a model for the effects of criticism, hostility and emotional over-involvement on patient symptoms and on therapy outcome. Such a model must explain the findings and include illness variables and personality features. For example, the patients' personality features and events in their lives are likely to influence their perception of criticism and the degree to which relatives respond to them with hostility. Further, trait anxiety is likely to affect both relatives' and patients' affective reactions (less positive reactions and more negative ones) and coping deficits, especially the lack of problem solving skills. Emotional over-involvement and accommodation to OCD symptoms may further reduce patients' self-efficacy and coping or problem solving skills. These features will undoubtedly contribute to state anxiety, avoidance and rituals. This model corresponds somewhat to the one proposed by Emmelkamp and colleagues for OCD described above. The implications of such a model and of the findings reported here are that it will be important to reduce relatives' hostility. This requires helping these relatives re-examine their attitudes toward the patient and the disorder and learn better problem-solving skills. If these methods fail, therapists may need to help patients distance themselves from these relatives.

Based on the research findings to date, we make the following several recommendations for intervention. We suggest psycho-educational interventions for family members who are unfamiliar with the disorder of OCD, who accommodate to patients' symptoms, and who tend to be critical and/or negative in their attitude. These interventions should include information about the biological, psychological, and social aspects of OCD, and about the adverse effects of family accommodation and strategies for extricating themselves from this type of behavior. For example, blaming the therapist is one way for family members to resist involvement in rituals such as reassurance seeking. Even more useful may be behavioral contracting in which family members agree aloud on who does what with whom to limit rituals and family involvement and increase exposure and reduction in obsessive anxiety. The effects of hostile criticism may best be addressed by determining the source of the hostility and correcting any blaming beliefs and attributions about the causes of the behavioral symptoms when this is feasible. Finally, family education should include information about the treatment procedures and their likely effects and side effects (e.g., patient distress from exposure and response prevention.

Only cooperative family members should be invited to assist in treatment, and instructed in the role of coach, supporter, and cheerleader. Desirable traits in relatives for assisting in treatment might be similar to those found helpful for therapists: respectful, understanding, interested, encouraging, challenging, explicit, sense of humor; not permissive or fostering dependency which have been found unhelpful. Excessive behavioral and emotional involvement should be discouraged so patients are able to undertake therapy decisions independently. Patients must learn for themselves how to tolerate exposure when obsessive thoughts intrude and they need to control rituals. Relatives may need to learn how to avoid arguments about tasks and roles during the therapy process while re-establishing normal family routines.

In addition, family therapy may be needed to support relatives in dealing with frustrating patient behaviors and to encourage more positive communication and reduce anger expression. Communication training has rarely been part of family treatments, except on an informal basis, but may be especially helpful regarding managing the symptoms themselves. Particularly for relatives who themselves are afflicted by OCD or by subclinical obsessive symptoms or personality traits (e.g., perfectionism, moral inflexibility), they may also need help to improve their own functioning. In such training, role playing of conversations, learning to identify and stop hostile comments, correcting of faulty beliefs about the patient, finding creative solutions for problems, and engaging in behavioral contracting may prove useful. Such interventions are likely to require longer treatments or perhaps sequential phases of treatment involving family members and working to increase patient skills and self-efficacy and relative's commu- 
nication and problem solving skills. These may prove especially helpful for treatment refractory patients who have not benefited readily from standard cognitive behavioral and pharmacological methods.

\section{References}

1. Steketee G, Pruyn N. Family functioning in OCD. In: Swinson RP, Antony MM, Rachman S, Richter MA, editors. Obsessive compulsive disorder: theory, research and treatment. New York: Guilford; 1998.

2. Lensi P, Cassano GB, Correddu G, Ravagli S, Kunovac JL, Akiskal HS. Obsessive-compulsive disorder: Familial-developmental history, symptomatology, comorbidity and course with special reference to genderrelated differences. Br J Psychiatry 1996;169:101-7.

3. Emmelkamp PMG, de Haan E, Hoogduin CAL. Marital adjustment and obsessive compulsive disorder. Br J Psychiatry 1990;156:55-60.

4. Steketee G. Social support and treatment outcome of obsessive compulsive disorder at 9-month follow-up. Behav Psychotherapy 1993;21:81-95.

5. Riggs DS, Hiss H, Foa EB. Marital distress and the treatment of obsessive compulsive disorder. Behav Therapy 1992;23:585-97.

6. Livingston-Van Noppen B, Rasmussen SA, Eisen J, McCartney L. Family function and treatment in obsessive-compulsive disorder. In:Jenike M, Baer L, Minichiello WE, eds. Obsessive compulsive disorder: theory and treatment. Chicago: Year Book Medical Publishers; 1990. p. 325-40.

7. Black DW, Noyes R, Goldstein RB, Blum N. A family study of obsessivecompulsive disorder. Arch Gen Psychiatry 1992;49:362-8.

8. Lenane MC, Swedo SE, Leonard H, Pauls DL, Sceery W, Rapoport J. Psychiatric disorders in first degree relatives of children and adolescents with obsessive compulsive disorder. J Am Acad Child Adolesc Psychiatry 1990;29:407-12.

9. Pauls DL, Raymond CL, Robertson M. The genetics of obsessivecompulsive disorder: a review. In: Zohar J, Insel T, Rasmussen S, editors. The psychobiology of obsessive-compulsive disorder. New York: Springer; 1991. p. 89-100.

10. Swedo SE, Rapoport JL, Leonard H, Lenane M, Cheslow D. Obsessive compulsive disorder in children and adolescents. Arch Gen Psychiatry 1989;46:335-41.

11. Black DW, Blum NS. Obsessive-compulsive disorder support groups: the Iowa model. Comprehensive Psychiatry 1992;33:65-71.

12. Bellodi L, Sciuto G, Diaferia G, Ronci P, Smeraldi E. Psychiatric disorders in the families of patients with obsessive-compulsive disorders. Psychiatry Res 1992;42:111-20.

13. Amir N, Freshman M, Foa EB. Family distress and involvement in relatives of obsessive-compulsive disorder patients. J Anxiety Dis 2000;14:209-17.

14. Honjo J, Hirano C, Murase S, Kaneko T, Sugiyama T, Ohtaka K, et al. Obsessive compulsive symptoms in childhood and adolescence. Acta Psychiatr Scand 1989;80:83-91.

15. Riddell MA, Scahill L, King R, Hardin MT, Towbin KE, Ort SI, et al. Obsessive compulsive disorder in children and adolescents: Phenomenolog and family history. J Am Academy Child Adolesc Psychiatry 1990;29:766-72.

16. Chambless DL, Gillis MM, Steketee G, Tran GQ. Parental bonding reports of clients with obsessive compulsive disordera and agoraphobia. Clin Psychol Psychotherapy 1996;3:77-85.

17. Bowlby J. A secure base. New York: Basic Books; 1988.

18. Cooper M. A group for families of obsessive-compulsive persons. Families in Society: J Contemporary Human Serv 1993;301-7.

19. Allsopp M, Verduyn C. Adolescents with obsessive compulsive disorder: a case note review of consecutive patients referred to a provincial regional adolescent psychiatry unit. J Adolesc 1990;13:157-69.

20. Calvocoressi L, Lewis B, Harris M, Trufan BS, Goodman WK, McDougle CJ, Price LH. Family accomodation in obsessive compulsive disorder. Am J Psychiatry 1995;152:441-3.

21. Calvocoressi L, Mazure C, Stanislav K, Skolnick J, Fisk D, Vegso S et al. Reliability and validity of the family accommodation scale for obsessivecompulsive disorder. J Nerv Mental Dis 1999;187:636-42.

22. Shafran R, Ralph J, Tallis F. Obsessive-compulsive symptoms and the family. Bull Menninger Clin 1995;59:472-9.

23. Hibbs ED, Hamburger SD, Lenane M, Rapoport JL, Kruesi MJP, Keysor CS, Goldstein MJ. Determinants of expressed emotion in families of disturbed and normal children. J Psychol Psychiatry 1991;32:757-70.

24. Hibbs ED, Hamburger SD, Kruesi MJP, Lenane M. Factors affecting expressed emotion in parents of ill and normal children. Am J Orthopsychiatry 1993;63:103-12.

25. Steketee G, Shapiro L. Predicting behavioral treatment outcome for agoraphobia and obsessive compulsive disorder. Clin Psychol Rev 1995;15:317-46.

26. Leonard HL, Swedo SE, Lenane MC, Rettew DC, Hamburger SD, Bartko JJ, Rapoport JL. A 2- to 7-year follow-up study of 54 obsessive-compulsive children and adolescents. Arch Gen Psychiatry 1993;50:429-39.

27. Hafner RJ. Marital interaction in persisting obsessive-compulsive disorders. Aust N Z J Psychiatry 1982;16:171-8.

28. Marks IM. New approaches to the treatment of obsessive-compulsive disorders. J Nerv Mental Dis 1973;156:420-6.

29. Chambless D, Steketee G. Expressed emotion and behavior therapy outcome: a prospective study with obsessive-compulsive and agoraphobic outpatients. J Consult Clin Psychology 1999;67:658-65.

30. Cobb J, McDonald R, Marks I, Stern R. Marital versus exposure therapy: psychological treatment of co-existing marital and phobic-obsessive problems. Behav Analysis Modif 1980;4:3-16.

31. Butzlaff R, Hooley J. Expressed emotion and psychiatric relapse: A metaanalysis. Arch Gen Psychiatry 1998:55:547-52.

32. Emmelkamp PMG, Kloek J, Blaauw E. Obsessive-compulsive disorders in principles and practice of relapse prevention. In: Wilson PH, editor. Principles and practice of relapse prevention. New York: Guilford; 1992. p. 213-34.

33. Peter H, Hand I. Patterns of patient-spouse interaction in agoraphobics: assessment by camberwell family interview (CFI) and impact on outcome of self-exposure treatment. In: Hand I, Wittchen H-U, editors. Panic and phobias 2: treatments and variables affecting course and outcome. Berlin: Springer-Verlag; 1988. p. 240-51.

34. Steketee G, Van Noppen B, Lam J, Shapiro L. Expressed emotion in families and the treatment of obsessive compulsive disorder. In Session: Psychotherapy in Practice 1998;4:73-91.

35. Marks IM, Hodgson R, Rachman S. Treatment of chronic obsessivecompuilsive neurosis with in vivo exposure: a 2-year follow-up and issues in treatment. Br J Psychiatry 1975;127:349-64.

36. Tynes LL, Salins C, Skiba W, Winstead DK. A psycho-educational and support group for obsessive-compulsive disorder patients and their significant others. Compr Psychiatry 1992;33:197-201.

37. Dalton P. Family treatment of an obsessive-compulsive child: a case report. Family Process 1983;22:99-108.

38. Fine S. Family therapy: a behavioral approach to childhood obsessive compulsive neurosis. Arch Gen Psychiatry 1973;28:695-7.

39. Hafner RJ, Gilchrist P, Bowling J, Kalucy R. The treatment of obsessional neurosis in a family setting. Austr N Z J Psychiatry 1981;15:145-51.

40. Emmelkamp PMG, DeLange I. Spouse involvement in the treatment of obsessive-compulsive patients. Behav Res Therapy 1983;21:341-6.

41. Mehta M. A comparative study of family-based and patient-based behavioural management in obsessive-compulsive disorder. Br J Psychiatry 1990; $157: 133-5$.

42. Hafner RJ. Anxiety disorders and family therapy. Aust N Z J Family Therapy 1992;13:99-104.

43. Jenkins JG, Karno M. The meaning of expressed emotion: theoretical issues raised by cross-cultural research. Am J Psychiatry 1992;149:9-21. 
44. Thornicroft G, Colson L, Marks IM. An inpatient behavioural psychotherapy unit description and audit. Br J Psychiatry 1991;158:362-7.

45. Grunes MS, Neziroglu F, McKay D. Family involvement in the behavioral treatment of obsessive-compulsive disorder: a preliminary investigation. Behav Therapy 2001;32:803-20.

46. Van Noppen B, Steketee G, McCorkle BH, Pato M. Group and multifamily behavioral treatment for obsessive compulsive disorder: a pilot study. J Anxiety Dis 1997;11:431-46.

47. Piacentini J, Jacobs C, Bergman RL et al. Cognitive behavior therapy for childhood obsessive-compulsive disorder: efficacy and predictors of treatment response. J Am Acad Child Adolesc Psychiatry; 2001.

48. Waters TL, Barrett PM, March JS. Cognitive-behavioral family treatment of childhood obsessive-compulsive disorder: preliminary findings. Am J Psychotherapy 2001;55:372-87.
49. Hiss H, Foa EB, Kozak MJ. Relapse prevention program for treatment of obsessive-compulsive disorder. J Consult Clin Psychol 1994;62:801-8.

\section{Correspondence:}

Gail Steketee

Boston University School of Social Work

264 Bay State Rd.

Boston, MA 02215

E-mail: steketee@bu.edu 